\title{
O Custo Privado da Reserva Legal para os Produtores Agropecuários de São Paulo e Mato Grosso nos Anos de 1995 e 2006 ${ }^{1,2}$
}

\author{
Samuel Alex Coelho Campos ${ }^{3}$ e Carlos José Caetano Bacha ${ }^{4}$
}

Resumo: Apesar de a reserva legal gerar benefícios ambientais e ecológicos, ela implica custos de oportunidade ao produtor agrícola. O objetivo deste artigo é estimar, por meio do modelo de folgas proposto por Zhou, Ang e Poh (2006), o custo de oportunidade da manutenção da reserva legal para os municípios dos estados de São Paulo e Mato Grosso nos anos de 1995 e 2006 (os dois últimos censos agropecuários). A metodologia considera o produtor médio por município e ajusta o número de municípios entre os anos citados segundo a proposta de Paiva $(2007,2008)$. Entre os resultados obtidos destacam-se: (a) a eficiência técnica e a técnica ambiental são pequenas nos dois estados analisados, mas cresceram entre os anos citados; (b) o custo de oportunidade de manutenção da reserva legal por estabelecimento é menor em São Paulo do que em Mato Grosso (R\$ 23.878 e $\mathrm{R} \$ 48.353$, respectivamente, em 2006), mas o custo por hectare é 2,22 vezes maior em São Paulo do que em Mato Grosso; (c) a disposição desses custos em mapas permite observar relações de similaridade ou não entre municípios vizinhos, o que permitirá, no futuro, explorar relações espaciais entre esses custos. Trabalhos futuros poderão, também, atualizar a análise deste artigo à medida que novos dados censitários estejam disponíveis.

Palavras-chaves: Custo de oportunidade; Reserva legal; Eficiência técnica; Eficiência técnica ambiental.

Abstract: In spite of the fact that the legal reserve generates several environmental benefits, it causes opportunity costs for the producer. This paper uses the Zou, Ang and Poh (2006)'s model to estimate the opportunity cost of holding the legal reserve inside each

1. Data de submissão: 16 de julho de 2015. Data de aceite: 6 de janeiro de 2016 .

2. Os autores agradecem à Fundação de Amparo à Pesquisa do Estado de São Paulo (Fapesp) pelo financiamento do projeto “Custo de oportunidade do Código Florestal entre 1995/1996 e 2006, sua evolução e seus determinantes", Processo n. 2013/19995-2.

3. Universidade Federal de Integração Latino-Americana. Foz do Iguaçu, Paraná, Brasil E-mail: s.alex.coelho@gmail.com

4. Universidade de São Paulo, Escola Superior de Agricultura "Luiz de Queiroz" - Esalq/USP. Piracicaba, São Paulo, Brasil. E-mail: carlosbacha@usp.br 
farm in São Paulo and Mato Grosso States (Brazil) in 1995 and 2006 (which correspond to the last two agricultural census). The methodology takes the average producer by municipality and adjusts the number of municipalities according to Paiva (2007 and 2008)'s method. Among the results, the following are highlighted: (1 ${ }^{\text {st }}$ ) both technical efficiency and environmental technical efficiency are small in both analyzed states, but they have grown up between the two analyzed years; $\left(2^{\text {nd }}\right)$ the opportunity cost of legal reserve is lower in São Paulo compared to that in Mato Grosso ( $R \$ 23,878$ and $R \$ 48,353$ per farm, respectively, in 2006), but the cost per hectare is 2.22 times higher in São Paulo in relation to Mato Grosso; $\left(3^{\text {rd }}\right)$ after displaying these costs on maps, some similarities and dissimilarities appeared among neighboring cities, which would be explored in the future by using spatial econometric techniques. New research might also be conducted about this paper's issue as new dataset becomes available.

Key-words: Opportunity cost; Legal reserve; Technical efficiency; Environmental technical efficiency.

DOI - http://dx.doi.org/10.1590/1234-56781806-9479005401004

Classificação JEL: D22, Q18, Q 23.

\section{Introdução}

A escolha por parte do produtor agropecuário do que e como produzir é determinada pela tecnologia de produção, pelo planejamento e pelos objetivos pessoais dos agricultores, os quais são delimitados por um conjunto de restrições ecológicas, sociais e econômicas (GIAMPIETRO, 1997) e pelas condições de infraestrutura e de apoio à produção.

Algumas restrições expressas na legislação - como as impostas pela Legislação Ambiental, especificamente, pelo Código Florestal - limitam a utilização da área total dos estabelecimentos agropecuários, ou seja, restringem o uso de pelo menos um dos insumos necessários à produção agropecuária e de elevada importância, que é a terra. A limitação no uso do solo estabelecida pelo Código Florestal se dá, principalmente, pela imposição da Área de Preservação Permanente (APP) e da reserva legal.

A limitação da área ocupada pela produção agropecuária advinda do Código Florestal se baseia nos benefícios que as matas nativas trazem para a sociedade, tais como a conservação da biodiversidade, dos recursos hídricos, da paisagem, da estabilidade geológica, entre outros ${ }^{5}$. Segundo Angelsen (2010) e Angelsen e Kaimowitz (1999),

5. Ver artigo $3^{\circ}$, incisos II e III da Lei n. 12.727 (BRASIL, 2012). esses benefícios podem ser classificados em três tipos: (i) produtos florestais privados: como madeira e produtos não madeireiros, controle da erosão e manutenção da fertilidade do solo, proteção contra pragas agrícolas, por exemplo; (ii) bens e serviços públicos locais: como manutenção da quantidade e qualidade da água, valores culturais e espirituais, serviços de polinização etc.; e (iii) bens e serviços globais: como mitigação das mudanças climáticas, conservação da biodiversidade e dos recursos genéticos, entre outros.

Nesse contexto, conforme Callan e Thomas (2010), a produção e o consumo se deparam com o dilema entre conservar o meio ambiente ou utilizar os recursos naturais para produzir bens e serviços para uso humano. Contudo, o processo de consumo dos recursos naturais também levará à produção de rejeitos que retornarão ao meio ambiente ${ }^{6}$. No entanto, a capacidade da natureza em transformar matéria e energia não é infinita ${ }^{7}$. Assim, da perspectiva social, é esperado que haja poluição do meio ambiente advinda da atividade

6. Na economia ecológica, essa é chamada de $1^{\text {a }}$ Lei da Termodinâmica. Segundo essa lei, matéria e energia não podem ser criadas ou destruídas. Assim, o fluxo de matéria e energia utilizados na produção de bens e serviços pela sociedade e consumidos por essa devem retornar como resíduos ao meio ambiente.

7. 2a Lei da Termodinâmica: "A capacidade da natureza de transformar energia não é ilimitada" (CALLAN e THOMAS, 2010, p. 7). 
econômica. Entretanto, cabe à sociedade decidir qual qualidade ambiental é aceitável e então fazer os ajustes necessários para obter essa qualidade ambiental, segundo Callan e Thomas (2010) e Perman et al. (2003). No entanto, não é desejável que o desmatamento seja nulo, uma vez que ele é necessário para a produção agropecuária e a consequente alimentação da população; entretanto, cabe à sociedade decidir qual grau de desmatamento é desejável ou tolerável.

Ademais, apesar de as florestas nativas gerarem benefícios locais e globais à sociedade essa última não paga por tais benefícios. Nesse sentido, o produtor rural percebe apenas os benefícios privados da floresta e, segundo Angelsen (2010), ele manterá a quantidade de florestas nativas na sua propriedade até o ponto em que a renda da agropecuária for igual aos benefícios privados oriundos da floresta. $\mathrm{O}$ produtor agropecuário reconhece a interdependência entre a produção agropecuária e o meio ambiente, no sentido que, por exemplo, um desmatamento excessivo pode resultar em erosão e perda da fertilidade do solo, o que reduzirá sua produtividade, aumentará os seus custos de produção e reduzirá sua renda. Entretanto, se o produtor mantiver uma área de floresta nativa maior do que a necessária para obter seus benefícios privados, o produtor estará sujeito a um custo de manutenção de uma área que gerará bens e serviços locais e globais, mas não receberá por isso, percebendo apenas um custo associado à produção renunciada. Para que o produtor seja incentivado a desmatar menos, ele deveria ser remunerado pela sociedade pelos benefícios locais e globais que a manutenção de áreas com florestas na sua propriedade fornece à sociedade ${ }^{8}$ (perspectiva de conservador - recebedor) ou o governo deve impor restrições à atividade agropecuária, sendo essa sujeita a multas pelo seu descumprimento, e taxas de uso dos recursos naturais, como a outorga pelo uso da água (perspectiva do poluidor - pagador).

8. Ver Angelsen (2010) para mais detalhes.
Na legislação brasileira, tem vigorado a perspectiva do poluidor pagador ${ }^{9}$, sendo o Código Florestal um exemplo disso. Esse código é uma ferramenta do tipo "comando-e-controle" que pode acarretar em um custo de oportunidade aos produtores agropecuários, podendo este custo corresponder ao valor de uso do solo no seu melhor destino alternativo por cada produtor rural (RICHARD e LEFTWICH, 1970), ao valor da produção renunciada (SIPILÄINEN e HUHTALA, 2013) e/ou aos custos advindos de utilizar mais insumos para se adequar a uma menor área explorável ou pela perda da produção ocasionada pela mudança na combinação necessária dos insumos para a redução do impacto ambiental, tal como sugerido por Zhou, Ang e Poh (2006).

A motivação do produtor para não manter a reserva legal e utilizar essa área para a produção agropecuária pode ser explicada pelo custo de oportunidade do cumprimento desta parte da legislação florestal, uma vez que essa área poderia ser incorporada no processo produtivo agropecuário e gerar renda para o agropecuarista. Entretanto, esse custo deve ser influenciado pelas peculiaridades de cada estabelecimento produtivo e pelos objetivos de cada produtor, bem como ser determinado pelo ambiente físico, econômico e social no qual o estabelecimento está inserido. Nesse sentido, a abordagem de Zhou, Ang e Poh (2006) permite assumir que os produtores são diferentes na forma como os insumos são utilizados na produção, obtendo, assim, custos de oportunidade diferenciados para cada produtor.

Dado o acima exposto, é interessante relacionar o padrão e a evolução da produção agropecuária entre aqueles estados de produção agropecuária consolidada, como São Paulo, aos estados de fronteira agrícola, como Mato Grosso, e o desmatamento em cada um, uma vez que cada estágio de desenvolvimento da produção

9. Essa perspectiva tem sido alterada. Como exemplo cita-se o artigo 41, inciso I do Novo Código Florestal (Lei n. 12.727 de 2012) que permite o "pagamento ou incentivo a serviços ambientais como retribuição, monetária ou não, às atividades de conservação e melhoria dos ecossistemas e que gerem serviços ambientais [...]." 
agropecuária submete a produção a restrições ambientais, sociais, econômicas e produtivas diferenciadas.

A diferença na dinâmica da agropecuária entre esses estados pode ser percebida entre os anos de 1970 e 2006, nos quais a área total dos estabelecimentos agropecuários em São Paulo diminuiu à taxa de $0,8 \%$ ao ano, enquanto a área de matas naturais cresceu à taxa de $0,7 \%$ a.a. Para o estado de Mato Grosso, a área total dos estabelecimentos e a área de matas naturais cresceram, aproximadamente, 2,5\% e 3,1\% ao ano, respectivamente. Assim, o percentual da área total dos estabelecimentos agropecuários ocupada com matas naturais cresceu de $7,2 \%$ para $11 \%$ para o estado de São Paulo, e de 32,4\% para 38,9\% no estado de Mato Grosso, de 1975 para 2006, respectivamente (segundo dados dos Censos Agropecuários).

Entretanto, se for considerado o período recente, a partir de 1995/96, Mato Grosso tem apresentado tendência de redução do percentual da área total dos estabelecimentos agropecuários ocupada com matas nativas. Em 1995/96, o percentual de matas naturais atingiu o pico de $43 \%$ da área total dos estabelecimentos agropecuários, reduzindo-se para 38,9\% em 2006. Destaca-se que a área dos estabelecimentos agropecuários ocupada com florestas naturais deveria representar, no mínimo, $20 \%$ e $63,5 \%{ }^{10}$ da área total dos estabelecimentos agropecuários de São Paulo e Mato Grosso, respectivamente, se fossem seguidas as normas sobre a reserva legal (não incluindo nesses percentuais as APPs).

Diante do acima exposto, o objetivo deste artigo é estimar, usando a metodologia de Zhou,

10. A área do estado de Mato Grosso coberta pelo bioma Amazônico, Cerrado e Pantanal representam 53,6\%, $39,6 \%$ e $6,8 \%$, respectivamente. Tanto o Código Florestal (Lei Ordinária n. 4.771/1965) e suas modificações, como o Novo Código Florestal (Lei Ordinária n. 12.651/2012) estabelecem que a área destinada à reserva legal nesses biomas deve ser de $80 \%$ e $35 \%$, sendo que a legislação para o Pantanal (Código Estadual do Meio Ambiente (artigo 62, LC n. 38/1995 e alterações) e Política Estadual de Gestão e Proteção à Bacia do Alto Paraguai no Estado de Mato Grosso (artigo 9o, LC n. 8.830/2008) ) não permite a retirada das matas, exceto para subsistência.
Ang e Poh (2006), o custo de oportunidade arcado por cada produtor rural representativo de São Paulo e Mato Grosso com a manutenção de áreas destinadas à reserva legal, tal como imposto pelo Código Florestal. Devido à necessidade de uso de dados dos Censos Agropecuários, a análise se restringe aos anos de 1995 e 2006 e considera-se o produtor médio por município.

Serão usados os limites da reserva legal definidos no Código Florestal de 1965 e suas modificações. Destaca-se que o Novo Código Florestal, Lei n. 12.727 (BRASIL, 2012), manteve a obrigação de áreas protegidas dentro das propriedades rurais (Reserva Legal e Áreas de Preservação Permanente) que estavam presentes no Código Florestal de 1965, Lei n. 4.771/65 (BRASIL, 1965), e suas alterações. Sendo que os percentuais da área dos estabelecimentos a serem mantidos como reserva legal, de acordo com os biomas brasileiros, não foram alterados pelo Novo Código Florestal, mas basicamente flexibilizou-se a obrigatoriedade de reposição da reserva legal. Dentre as principais mudanças presentes no Novo Código Florestal destacam-se: (1) introduziu-se o conceito de áreas consolidadas (que são áreas ocupadas com atividades agropecuárias antes de 22 de junho de 2008 e onde o Código Florestal de 1965 vedava seu uso), para as quais não haveria multas pelo desmatamento; (2) permite-se, em alguns casos, que a área da APP seja contabilizada na área de RL; e (3) pequenos imóveis, que não tinham reserva legal, foram isentados de sua recomposição.

O uso de dados de 2006, ainda que não atuais, permitem avaliar os tópicos que são objetivos deste artigo, estimando o que os produtores rurais já perderam. À medida que novos dados censitários sejam disponíveis, os cálculos a serem apresentados poderão ser atualizados e comparados entre si.

Este artigo está dividido em mais quatro partes. A seguir, apresenta-se a revisão de literatura (teórica e empírica) mais próxima ao objetivo do artigo. Na seção 3 apresenta-se a metodologia adotada no artigo, seguida pela apresentação dos resultados na seção 4 . A seção 5 apresenta as conclusões do artigo, seguidas das referências bibliográficas adotadas no texto. 


\section{Revisão de literatura}

O trade-off entre a produção econômica e a degradação ambiental - especificamente dentro do contexto desse estudo, entre a produção agropecuária e o desmatamento das florestas tem sido estudado no contexto da economia dos recursos naturais utilizando o conceito de falhas de mercado, baseando-se na teoria das externalidades, ou na teoria dos bens públicos (CALLAN e THOMAS, 2010). Esse debate tem confrontado "conservacionistas" e "produtivistas" (ou "ruralistas", especificamente no contexto da produção agropecuária). Os primeiros defendem os benefícios que os recursos naturais geram para a sociedade, devendo esses recursos naturais serem conservados. Os "produtivistas" defendem que os recursos naturais devem ser utilizados no processo de produção para gerar alimentação, matérias-primas e promover o crescimento econômico (ANDERSEN et al., 2002).

O problema no uso das florestas nativas advém do fato de que o mercado não é capaz de produzir uma alocação eficiente dessas florestas. Os serviços ambientais produzidos pelas florestas apresentam características de um bem público, no sentido de que esses serviços (como a conservação do clima, por exemplo) não estão sujeitos aos direitos de propriedade e o acesso a eles é livre para toda a população ${ }^{11}$. Os produtores rurais não seriam capazes de obter receita ao fornecer esses bens e serviços para toda a sociedade.

Da perspectiva da teoria das externalidades, o consumo dos recursos naturais implica um transbordamento sobre uma terceira parte (CALLAN e THOMAS, 2010). Esse transbordamento pode ser positivo (externalidade positiva) ou negativo (externalidade negativa). Nesse sentido, o desmatamento resultaria em uma externalidade negativa à medida que reduz a oferta dos serviços ambientais florestais, podendo levar ao assore-

11. Um bem público puro é caracterizado pela não rivalidade (o consumo por um agente não impede o consumo por outro agente) e pela não exclusividade do consumo - não há, ou o custo é excessivamente elevado, como excluir um agente que não pagou do consumo (PERMAN et al., 2003). amento e aumento da quantidade de sedimentos nos rios, aumentando o custo de tratamento da água, por exemplo. Por outro lado, a conservação das florestas gera externalidades positivas para toda a sociedade na forma de sequestro de carbono, regulação de bacias hidrográficas, entre outros. As externalidades positivas elevariam o bem-estar da população, sendo que o agente responsável por esse ganho de bem-estar deveria ser remunerado. Entretanto, o Código Florestal "tenta corrigir uma falha (externalidade negativa) impondo outra (externalidade positiva), às expensas de um pequeno grupo social diretamente ligado ao recurso" (SIQUEIRA, 2004, p. 46).

Na visão supramencionada, o produtor agropecuário oferta um serviço ou bem ambiental, não sendo remunerado por isso. Nesse sentido, as florestas representariam um custo (de oportunidade) para os produtores. Esse custo tem sido calculado na literatura por meio de duas metodologias principais, em que: (i) utilizam indicadores de lucratividade e comparam a rentabilidade da produção agropecuária quando a propriedade conserva a reserva legal e essa não apresenta uso econômico, ou comparam propriedades que praticam o manejo sustentável com propriedades que utilizam toda a área do estabelecimento para a produção agropecuária (sem ter reserva legal) ou apresentam área de reserva legal menor do que o exigido em lei (AZZONI e ISAI, 1994; BACHA, 2005; CAMPOS e BACHA, 2013; CARNEIRO, 2005; IGARI, TAMBOSI e PIVELLO, 2009; FASIABEN et al., 2011); (ii) estimam o custo de oportunidade de ter a reserva legal por meio de uma função distância, considerando a perda da produção ocasionada pela mudança na combinação dos insumos necessária para a redução do impacto ambiental e incorporam desperdícios no uso dos insumos por parte dos produtores (COELLI, LAUWERS e HUYLENBROECK, 2007; HUHTALA e MARKLUND, 2008; SIPILÄINEN e HUHTALA, 2013; ZHOU, ANG e POH, 2006).

Os estudos do primeiro grupo supracitado assumem que todos os produtores utilizam a mesma tecnologia, representada pelas estimativas dos fluxos de caixa, e/ou desconsideraram que, 
mesmo que os produtores utilizem uma mesma tecnologia, a produção por hectare desmatado (e o custo de oportunidade) pode diferir significativamente em virtude da eficiência de produção, conforme destacado por Lee, Park e Kim (2002) e Sipiläinen e Huhtala (2013). Ademais, o valor do custo de oportunidade também é sensível à taxa de retorno considerada (IGARI, TAMBOSI e PIVELLO, 2009). Destarte, as firmas podem utilizar uma tecnologia de produção mais extensiva em terra, pela ausência de motivação interna que proporcione a internalização dos custos ambientais, o que, consequentemente, resulta em maior necessidade de desmatamento (FÄRE, GROSSKOPF e TYTECA, 1996).

Acrescenta-se às críticas do parágrafo anterior que, devido à informação assimétrica, o regulador não necessariamente conhece o custo de conservação dos fazendeiros advindo das diversas políticas ambientais (SIPILÄINEN e HUHTALA, 2013). Assim, o padrão de regulação final é fortemente influenciado pelos limites experimentais (ZOFÍO e PRIETO, 2001).

Como forma de contornar essas limitações, o presente artigo utiliza a metodologia baseada na função distância proposta por Zhou, Ang e Poh (2006), ainda não utilizada no Brasil, para atingir o objetivo deste artigo. Essa metodologia incorpora a ineficiência produtiva por meio do desvio do produtor de uma fronteira de possibilidades de produção estimada. Essa fronteira toma como melhor tecnologia aquela efetivamente adotada pelos produtores (da amostra). Essa metodologia apresenta menor restrição quanto à tecnologia, permite que as firmas sejam heterogêneas e apresentem custos de oportunidade diferentes por unidade produzida e permite a identificação de fazendas benchmarks, que podem ser utilizadas como padrão para seus pares.

\section{Metodologia}

A metodologia proposta por Zhou, Ang e Poh (2006), baseada em Tone (2001), consiste em, inicialmente, estimar a eficiência técnica e, em seguida, incorporar a restrição ambiental, estimando a eficiência técnica ambiental. A partir desses dois indicadores de eficiência (técnica e técnica ambiental), calcula-se o Índice de Eficiência Baseado nas Folgas (SBEI), o qual indica o percentual da receita agropecuária que seria possível ao produtor obter ao respeitar a legislação florestal, comparada àquele produtor que não respeita a restrição ambiental.

Essa metodologia permite o cálculo comparativo do desempenho dos produtores, considerando o desmatamento (produto indesejável) e a relação entre produtos desejáveis e insumos. São consideradas várias dimensões e não apenas uma razão simples entre um produto indesejável, um produto desejável ou um insumo.

A eficiência técnica $\left(\tau_{1}\right)$ pode ser estimada pela seguinte expressão linear, segundo Tone (2001):

$$
\min \tau_{1}=t-\frac{1}{m} \sum_{i=1}^{m} s_{i}^{-} / x_{i o}
$$

s.a.

$$
\begin{aligned}
& 1=t+\frac{1}{S} \sum_{r=1}^{s} S_{r}^{+} / y_{r o} \\
& t x_{0}=X \Delta+S^{-} \\
& t y_{o}^{g}=Y^{g} \Delta-S^{+} \\
& \Delta \geq 0, \mathrm{~S}^{-} \geq 0, \mathrm{~S}^{+} \geq 0 \text { e } \mathrm{t}>0 \\
& \text { O termo } X=\left(x_{k}\right) \in R_{+}^{n x k} \text { denota a matriz de }
\end{aligned}
$$
insumos; $Y^{g}=\left(y_{k}^{g}\right) \in R_{+}^{m x k}$ é a matriz de produtos desejáveis (produtos agropecuários); em que ké o número de produtores agropecuários $\left(\mathrm{DMUs}^{12}\right), \mathrm{n}$ é o número de insumos e m é o número de produ-

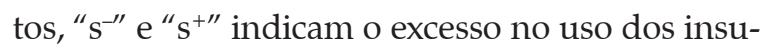
mos e o déficit da produção, respectivamente; “ $\lambda$ " é o vetor de intensidade, " $t$ " é um escalar positivo $\mathrm{e}$ " $\tau_{1}$ " é o vetor dos escores de eficiência técnica calculado para cada DMU, que assume valores entre 0 e 1. Esse modelo considera que as firmas não sofrem restrições ambientais regulatórias e não

12. DMU - Decision Making Unit; no nosso caso será o produtor médio por município. 
há custo associado à produção de produtos indesejáveis (PICAZO-TADEO, REIG-MARTÍNEZ e HERNÁNDEZ-SANCHO, 2005).

Como forma de incorporar os produtos indesejáveis no cálculo da eficiência técnica, Zhou, Ang e Poh (2006) modificaram a expressão (1) e incorporam uma restrição para os produtos indesejáveis $\left(t y_{0}^{b}=Y^{b} \Delta\right)$, o que permite estimar um vetor $\tau_{2}$ de eficiência técnica ambiental, calculado para cada DMU e que assume valores entre 0 e 1 . A restrição $t y_{0}^{b}=Y^{b} \Delta$ altera a escolha no uso de insumos e produção, podendo restringir o uso dos insumos, direcionando parte dos esforços produtivos para reduzir os produtos indesejáveis, como o desmatamento das áreas que deveriam ser mantidas como reserva legal dentro do estabelecimento. A expressão (1) estima a eficiência sobre a pressuposição de retornos constantes à escala. Para obter a eficiência sobre a pressuposição de retornos variáveis à escala basta adicionar a restrição $\sum_{k=1}^{K} \lambda_{k}=1$.

Por meio de $\tau_{1}$ e $\tau_{2}$, Zhou, Ang e Poh (2006) definem um Índice de Eficiência Baseada nas Folgas (Slacks Based Efficiency Index - SBEI) para modelar o impacto econômico da regulação ambiental. SBEI é dado por:

$$
S B E I=\tau_{1} / \tau_{2}
$$

Se $S B E I=1$, a restrição ambiental não implica custo produtivo à DMU, enquanto se $S B E I<1$ há indicação de que a regulação ambiental não permite a utilização produtiva de todos os insumos na quantidade adequada, comprometendo a capacidade da DMU em transformar insumos em produtos.

Quantitativamente, o custo da regulamentação ambiental pode ser calculado como:

Custo de oportunidade de manter a RL = $=(1-\mathrm{SBEI})^{*}$ receita agropecuária

Assim, se houver custo de oportunidade, não será possível reduzir o produto indesejável (desmatamento da reserva legal) sem que o produto desejável (receita agropecuária) seja reduzido. Desta forma, a regulação (imposta pelo Código Florestal) restringe o processo produtivo, forçando a redução da receita agropecuária nos estabelecimentos agropecuários para o cumprimento da legislação - a manutenção da reserva legal (ZOFÍO e PRIETO, 2001). Nesse sentido, o produtor arcará com o custo de criação de externalidades positivas para toda a sociedade (como a manutenção da qualidade e quantidade da água, mitigação das mudanças climáticas, paisagem cênica etc.) mas não recebendo qualquer contrapartida monetária. Ademais, a restrição ambiental pode resultar em ineficiência produtiva: uma firma pode ser ineficiente tecnicamente por utilizar mais insumos por unidade de produto (desejável) como forma de reduzir o impacto ambiental (BOYD e McCLELLAND, 1999).

\subsection{Variáveis utilizadas para calcular o custo de oportunidade da reserva legal}

A estimativa do custo de oportunidade considera como unidade de análise o produtor médio de cada município, obtido pela divisão do valor total das variáveis de produto, insumo e produto indesejável de cada município pelo seu respectivo número de estabelecimentos.

Para o cálculo da expressão (1) foram utilizadas as seguintes variáveis, obtidas do Censo Agropecuário de 1995/1996 e 2006:

Receita agropecuária (produto desejável): somatório das receitas dos estabelecimentos agropecuários com a venda de produtos vegetais; animais e seus produtos; animais criados em cativeiros (jacaré, escargô, capivara e outros); húmus; esterco e produtos da indústria rural, em mil reais de dezembro de 2006/Número de estabelecimentos agropecuários do município. Este é o $Y^{\mathrm{g}}$ da expressão (1).

A matriz $X$ da expressão (1) é composta por:

- Área produtiva: área total dos estabelecimentos menos a área com matas e florestas naturais, menos a área com terras produtivas não utilizadas e terras inaproveitáveis para o ano de 1995. Para 2006 também foi subtraída a área com matas e florestas naturais destinadas à preservação permanente ou reserva legal, matas e florestas 
naturais (exceto aquelas destinadas à preservação permanente e aquelas em sistemas agroflorestais) e as áreas de tanques, lagos, açudes, áreas de águas públicas para exploração de aquicultura ${ }^{13}$, terras degradadas (erodidas, desertificadas, salinizadas etc.) e terras inaproveitáveis à agricultura ou pecuária (pântanos, areais, pedreiras etc.)/número de estabelecimentos agropecuários do município;

- Mão de obra: total do pessoal ocupado em estabelecimentos agropecuários em 31/12 para 1995 e em 31/12 para 2006 dividido pelo número de estabelecimentos agropecuários do município;

- Bovinos: efetivo de bovinos nos estabelecimentos agropecuários (em cabeças) dividido pelo número de estabelecimentos agropecuários do município;

- Defensivos: compreende as despesas com fertilizantes, pesticidas e herbicidas, combustível, sementes e alimentos e medicamentos para os bovinos (em reais de dezembro de 2006) dividido pelo número de estabelecimentos agropecuários do município; e

- Tratores: número de tratores existentes nos estabelecimentos agropecuários dividido pelo número de estabelecimentos agropecuários do município.

Para o cálculo da eficiência técnica ambiental foram utilizadas as mesmas variáveis do cálculo da eficiência técnica, acrescentando a variável "desmatamento da reserva legal" (produto indesejável, $y^{\mathrm{b}}$ ): calculada como sendo a área utilizada para a produção agropecuária acima do percentual de $65 \%$ para a região de $\mathrm{MT}^{14}$ coberta com Cerrado, $20 \%$ para região de floresta em

13. No Censo Agropecuário de 1995/96, as áreas ocupadas com tanques, lagos, açudes, áreas de águas públicas para exploração de aquicultura são classificadas como "inaproveitáveis para lavoura e pecuária", segundo IBGE (2009)

14. O percentual da área coberta com cada bioma em cada município foi obtido em Brasil (2010). Então, foram calculados os referidos percentuais para cada bioma por município.
MT e $80 \%$ para o restante (desconsiderando o Pantanal). Para São Paulo será considerado o percentual de $80 \%$.

Destaca-se que os dados mais recentes em nível municipal para todas as variáveis necessárias ao estudo são os dos Censo Agropecuário de 2006. Ainda que esses dados não sejam atuais, eles permitem avaliar o que o produtor agropecuário já teve de custo de oportunidade para manter a reserva legal e, portanto, uma reflexão sobre esse custo.

Os valores monetários foram corrigidos para dezembro de 2006, sendo utilizado o índice de preços recebidos pelos agricultores por unidade da federação (FUNDAÇÃO GETÚLIO VARGAS - FVG, 1996, 2007) para a receita agropecuária e o índice de preços pagos pelos agricultores por unidade da federação (FVG, 1996, 2007) para os insumos agropecuários. Esse procedimento objetivou permitir variações nos termos de troca e entre os estados em análise. Ademais, a utilização de diferentes índices de deflacionamento (que melhor captem a mudança nos valores da variável de interesse ao longo do tempo) permite um melhor ajustamento do modelo DEA, conforme enfatizado por Coelli et al. (2005).

Naqueles municípios em que não for possível obter alguma das variáveis a serem analisadas - por questão de sigilo dos dados (pois o Censo Agropecuário omite os dados para os municípios que possuem menos de três estabelecimentos agropecuários, os apresentando como valor " $X$ " para evitar a individualização da informação) ou que apresentaram receita agropecuária igual a zero não resultante de arredondamento (representada por “-"), em apenas um período ou em ambos - foram retirados da análise em ambos os anos analisados (1995/96 e 2006) de forma a permitir a comparação entre os anos e manter o mesmo número de municípios em cada ano.

Ademais, como entre os anos analisados foram criados municípios, os números de municípios de São Paulo e Mato Grosso foram compatibilizados segundo a metodologia proposta por Paiva (2007, 2008). Para o estado de Mato Grosso, os municípios que possuem parte de sua 
Tabela 1. Estatísticas descritivas para as estimativas de eficiência técnica, técnica ambiental e SBEI para São Paulo e Mato Grosso nos anos de 1995/96 e 2006

\begin{tabular}{|c|c|c|c|c|c|}
\hline Variáveis & Observações & Média & Desvio Padrão & Mínimo & Máximo \\
\hline \multicolumn{6}{|l|}{ Mato Grosso, 1995/96 } \\
\hline Eficiência técnica $\left(\tau_{1}\right)$ & 103 & 0,19 & 0,09 & 0,09 & 0,69 \\
\hline Eficiência técnica ambiental $\left(\tau_{2}\right)$ & 103 & 0,32 & 0,22 & 0,10 & 1 \\
\hline SBEI & 103 & 0,69 & 0,17 & 0,16 & 1 \\
\hline \multicolumn{6}{|l|}{ Mato Grosso, 2006} \\
\hline Eficiência técnica $\left(\tau_{1}\right)$ & 103 & 0,24 & 0,11 & 0,10 & 1 \\
\hline Eficiência técnica ambiental $\left(\tau_{2}\right)$ & 103 & 0,38 & 0,22 & 0,11 & 1 \\
\hline SBEI & 103 & 0,70 & 0,16 & 0,25 & 1 \\
\hline \multicolumn{6}{|l|}{ São Paulo, 1995/96 } \\
\hline Eficiência técnica $\left(\tau_{1}\right)$ & 592 & 0,27 & 0,16 & 0,07 & 1 \\
\hline Eficiência técnica ambiental $\left(\tau_{2}\right)$ & 592 & 0,38 & 0,21 & 0,07 & 1 \\
\hline SBEI & 592 & 0,75 & 0,17 & 0,32 & 1 \\
\hline \multicolumn{6}{|l|}{ São Paulo, 2006} \\
\hline Eficiência técnica $\left(\tau_{1}\right)$ & 592 & 0,30 & 0,19 & 0,10 & 1 \\
\hline Eficiência técnica ambiental $\left(\tau_{2}\right)$ & 592 & 0,43 & 0,23 & 0,10 & 1 \\
\hline SBEI & 592 & 0,72 & 0,19 & 0,23 & 1 \\
\hline
\end{tabular}

Nota: Destaca-se que o cálculo do desempenho foi executado considerando apenas uma fronteira de produção, o que permite a comparação das estimativas.

Fonte: Resultados da Pesquisa.

área inserida no bioma Pantanal foram retirados da análise, uma vez que esse bioma apresenta características próprias e que tornam a produção agropecuária limitada, principalmente quando se considera as enchentes periódicas ${ }^{15}$ (BRASIL, 2010). Após esses procedimentos foram totalizadas 1.390 observações para cada variável (correspondentes a 592 municípios de São Paulo e 103 municípios de Mato Grosso considerados em dois anos).

Para a variável "desmatamento" foi necessário utilizar um procedimento para que ela apresentasse valores maiores do que zero, como suposto pela função de produção. Essa variável apresentou valores negativos para alguns municípios uma vez que eles apresentavam área de matas nativas superior à legalmente exigida para o desmatamento da reserva legal, o que implicou em desmatamento "negativo". O procedimento adotado consiste em adicionar uma constante a todas as observações daquela variável que apre-

15. Como dito anteriormente, a Lei n. 8.830/2008 no seu Artigo 9o proíbe a implantação de projetos agrícolas, exceto a atividade agrícola de subsistência e a pecuária extensiva, na Planície Alagável da Bacia do Alto Paraguai de Mato Grosso. sentam valores nulos ou negativos, de forma que os novos valores dessa variável sejam positivos e maiores do que zero. Nesse sentido, foi necessário adicionar o valor de 330,750 para que a variável que mensura o desmatamento da reserva legal apresentasse valor positivo e maiores do que zero. Esse método é largamente utilizado na literatura que trata da Análise Envoltória de Dados e é chamado de "translation". Quando se utiliza esse procedimento é necessário atentar-se que o resultado ótimo não será alterado, ou seja, o resultado seja "translation invariant" (SHARP, MENG e LIU, 2007).

\section{Resultados}

Os valores médios para a eficiência técnica para os estados e por ano de análise (Tabela 1) indicam que o desempenho médio dos municípios foi baixo nos anos 1995/96 e 2006, sendo a menor média para o estado de Mato Grosso em 1995/96, de apenas 0,19 ou 19\%. Haveria, assim, um desperdício de aproximadamente $81 \%$, na média, dos recursos produtivos. Chama também a atenção que o maior escore de eficiência técnica 
para a produção agropecuária no Mato Grosso em 1995/96 tenha sido de apenas 0,69 ou $69 \%$, não apresentando nenhum município tecnicamente eficiente nesse ano. Isso indica que nenhum dos municípios de Mato Grosso pode ser considerado como tecnicamente eficiente. Este resultado pode advir do uso em excesso de insumos, baixa produção do produto desejável (receita agropecuária) ou ambos, que pode ser identificado e estimado por meio das folgas dos insumos e produtos. A ineficiência técnica pode ser atribuída à falta de treinamento quanto às técnicas de produção, como controle de pragas, doenças, plantas daninhas (KEIL, BIRNER e ZELLER, 2007) e às falhas no acesso à informação (PIOT-LEPETIT, VERMERSCH e WEAVER, 1997).

A proibição do desmatamento da área que deve ser mantida como reserva legal aumentou a homogeneidade dos produtores em relação à distância da fronteira de produção, de forma que o escore de eficiência aumentou em 13 pontos percentuais, em média, para todos os dois estados analisados. Por exemplo, a eficiência técnica de SP em 2006 foi de 0,30, enquanto sua eficiência ambiental foi de 0,43 , um aumento de 13 pontos percentuais. $\mathrm{O}$ maior aumento relativo foi para o estado de Mato Grosso em 1995/96, que elevou em $68 \%$ sua eficiência, que aumentou de 0,19 para 0,32 , muito embora esse seja o estado com menor desempenho, tanto ambiental como técnico, entre os dois estados analisados.

Mato Grosso também foi aquele que apresentou o maior custo de oportunidade em função da restrição ambiental definida pela manutenção da reserva legal (indicado por meio da média para SBEI). Em 1995, o código florestal implicou queda na receita (potencial) dos produtores mato-grossenses de $31 \%$ [(1-0,69)*100], permanecendo essa queda relativa praticamente inalterada em 2006 (em 30\%). Para São Paulo, esses percentuais foram de $25 \%$ e $28 \%$, respectivamente.

Os resultados da Tabela 1 indicam que não houve melhoria significativa no gerenciamento da produção agropecuária entre 1995/96 e 2006, uma vez que, na média, há um elevado desperdício ou mau uso dos insumos para a geração do produto agropecuário (receita). Esses resultados também podem ser atribuídos à tecnologia de produção, ou seja, o número de produtores agropecuários que utilizam uma tecnologia inadequada e defasada com equipamentos depreciados pode ser elevado, implicando em desperdício no uso dos insumos e menor produtividade. A defasagem da tecnologia pode ser explicada pela menor proporção do crédito de investimento sobre o valor do crédito total. Ademais, pode-se inferir que a forma como os produtores gerenciam a área de reserva legal não apresentou modificações, sendo que o sistema produtivo continuou dependente da área de reserva legal, de forma que a adequação à legislação florestal com a redução da utilização da área da Reserva no processo produtivo agropecuário implicaria em elevados custos para os produtores.

O custo de oportunidade motiva o agropecuarista a incorporar parte da área da reserva legal no processo de produção, e, consequentemente, não cumprir com a legislação florestal. O desrespeito da legislação pode ser atribuído à fraca fiscalização e à valorização da terra, que compensaria o valor das multas (IGARI, TAMBOSI e PIVELLO, 2009). Segundo Ehlers (2003), que analisou o aumento das áreas de floresta na Mata Atlântica no estado de São Paulo, uma fiscalização mais severa e políticas para o desenvolvimento do ecoturismo seriam estratégias que incentivariam os produtores a adotar práticas de produção menos dependentes das áreas da reserva legal.

Comparando a diferença de desempenho dos produtores mato-grossenses em 1995/96 nota-se que enquanto o desempenho técnico máximo atingido pelos seus municípios nesse período foi 69\%, 15 municípios atingiram a eficiência ambiental (escore de eficiência igual à unidade), havendo uma correlação de $81,89 \%$, significativa a 1\%, entre essas duas variáveis. Assim, embora o cálculo da eficiência técnica desconsiderando a RL tenha penalizado alguns produtores que apresentavam uma maior área coberta com matas mas que produziam menos, implicando em melhor cumprimento da legislação florestal, esse resultado indica, a princípio, uma relação 
positiva entre a proteção ambiental (considerando a manutenção da RL) e a eficiência técnica para esse estado em 1995/96. Essa relação também foi encontrada por Wilson, Hadley e Asby (2001), que consideraram que os produtores mais preocupados com o meio ambiente indiretamente utilizavam os insumos de forma mais eficiente, evitando desperdícios.

Quando se comparam os valores médios para os estados entre os anos constata-se que São Paulo apresentou o melhor desempenho, seja técnico ou ambiental. Souza e Gomes (2015) encontraram relação semelhante, muito embora analisaram a eficiência econômica dos estados brasileiros para 1995/1996 e 2006, em que o estado de Mato Grosso obteve eficiência média de 0,28 , enquanto o estado de São Paulo foi eficiente em ambos os períodos. Esse estudo também indicou a melhoria no desempenho no estado de Mato Grosso, de 0,20 para 0,36 . O melhor desempenho do estado de São Paulo em relação a Mato Grosso pode ser explicado pela pressão por eficiência advinda do maior custo dos fatores de produção em São Paulo, como a terra e mão de obra. Em dezembro de 2006, por exemplo, 1 hectare de lavoura custava em Mato Grosso e São Paulo, respectivamente, R\$ 4.485,62 e R\$ 9.940,44 (FGV, 2014).

Os resultados encontrados para a eficiência ambiental (Tabela 1) também são semelhantes a outros estudos, como Sun et al. (2014), que analisaram a eficiência ambiental do uso da água para 31 províncias da China entre 1997 e 2011 utilizando o modelo baseado nas folgas proposto por Tone (2004) e incorporam como insumos a pegada hídrica (que reflete o consumo direto e indireto de água); o consumo total de água na agricultura, indústria e ecológico (pelo ecossistema); a força de trabalho e o investimento em ativos fixos. Como produto desejável foi utilizado o Produto Interno Bruto e como produto indesejável a pegada hídrica cinza $^{16}$. As estimativas para eficiência ambiental obtidas por Sun et al. (2014) apresentaram valor

16. A pegada hídrica cinza é definida como a quantidade de água necessária para diluir os poluentes de forma que a qualidade da água alcance um padrão definido aceitável (SUN et al., 2014). médio de 0,20. A estimativa para a eficiência ambiental para o uso da água nesse estudo apresentou melhoria ao longo do período de análise. A média do escore de eficiência de apenas 0,08 em 1997 aumentou para 0,43 em 2011.

\subsection{Custo de oportunidade da reserva legal}

O custo de oportunidade dos produtores agropecuários em conservar a reserva legal pode ser captado pelo Índice de Eficiência Baseado nas Folgas (expressão 2 do item 3 ), que varia no intervalo de 0 a 1 , sendo o intervalo aberto em 0 . Valor igual a 1 indica que a reserva legal não implica custo de oportunidade ao produtor agropecuário. Quanto mais próximo de 1 for SBEI, menor é a proporção do custo em relação à receita agropecuária; e quanto mais próximo de 0 for SBEI, maior é esse custo proporcionalmente à receita agropecuária obtida pelo estabelecimento agropecuário.

Observando os valores de SBEI, pode-se inferir que a exigência da reserva legal implicou custo de oportunidade para um elevado número de produtores. Para o estado de Mato Grosso, apenas $6 \%$ e 5\% dos produtores em 1995/96 e em 2006, respectivamente, apresentaram SBEI maior do que $96,67 \%$. Para o estado de São Paulo, esses percentuais foram $16 \%$ e $15 \%$, respectivamente. De forma geral, o custo médio da regulação sobre a produção agropecuária - representado, em termos percentuais, por meio do Índice de Eficiência Baseado nas Folgas (SBEI) - indica que a regulação ocasionou, para $90 \%$ do total dos produtores, tanto em 1995 como em 2006, em custos à produção agropecuária.

A regulação apresentou maior impacto para os municípios de Mato Grosso em 1995/96 e em 2006, apresentando custo de oportunidade de $31 \%$ e $30,2 \%$ da receita agropecuária, respectivamente (Tabela 2). Esse estado foi também o que apresentou o maior número de produtores com custo de oportunidade, $96 \%$ de seus produtores. Quando se considera todos os produtores analisados de ambos os estados, obtém-se o percentual médio de redução da receita agropecuária de $26 \%$ e $28 \%$ para 1995 e 2006, respectivamente. 
Destaca-se que, se um município apresenta baixo desempenho ambiental, não necessariamente apresentará elevado custo de oportunidade, conforme destacou Zhou, Ang e Poh (2006). A correlação de Sperman entre a eficiência ambiental e o SBEI foi de - 0,7829 , estatisticamente significativa a $1 \%$, para o estado de Mato Grosso em 2006. Entretanto, quando se analisa a correlação de Sperman entre a eficiência ambiental e o custo de oportunidade e o SBEI e o custo de oportunidade para o estado de Mato Grosso em 2006 obtêm-se as estimativas de -0,0720 e -0,0114, respectivamente, mas não estatisticamente significativas ao nível de significância de 10\%. Tomando como exemplo o estado de Mato Grosso em 2006 (Tabela 1) constata-se que ele apresentou ineficiência técnica de $76 \%$ e ineficiência ambiental de $62 \%$. Esses resultados implicam uma queda média na receita agropecuária de 30,2\% (Tabela 2 ), ou seja, $\mathrm{R} \$ 48.353$ por produtor representativo (Tabela 3).
Quando se considera a sua área total, o estado de Mato Grosso apresentou o maior valor para o custo de oportunidade do que o estado de São Paulo (Tabela 3). Entretanto, esse valor pode ser maior pelo fato de a área total dos estabelecimentos no primeiro estado também ser maior do que a área utilizada na agropecuária no estado de São Paulo.

Como forma de contornar essa limitação, o custo de oportunidade da reserva legal por hectare utilizado na produção agropecuária foi calculado (Tabela 4). Os resultados indicam que o custo é maior para São Paulo do que para Mato Grosso. Essa relação não é estranha, visto que o valor de cada hectare de terra em 2006 é maior para São Paulo do que para Mato Grosso - o valor do hectare em SP foi 2,22 vezes maior do que do MT (segundo dados da Fundação Getúlio Vargas).

As estimativas da Tabela 4 também indicam que o custo de oportunidade médio dos produtores de São Paulo reduziu-se no período analisado de $\mathrm{R} \$ 484,36$ para $\mathrm{R} \$ 412,62$ (ambos a preços de dezem-

Tabela 2. Redução percentual média da receita agropecuária para os municípios advinda da reserva legal, por Unidade da Federação e período de análise

\begin{tabular}{lcc}
\hline \multicolumn{1}{c}{ UF/Período } & $\mathbf{1 9 9 5 / 9 6}$ & $\mathbf{2 0 0 6}$ \\
\hline Mato Grosso & $31,0 \%$ & $30,2 \%$ \\
São Paulo & $25,1 \%$ & $27,5 \%$ \\
Mato Grosso e São Paulo & $26 \%$ & $28 \%$ \\
\hline
\end{tabular}

Fonte: Resultados da pesquisa.

Tabela 3. Custo médio por estabelecimento agropecuário da reserva legal em Reais de dezembro de 2006, Mato Grosso e São Paulo, anos de 1995/96 e 2006

\begin{tabular}{lcc}
\multicolumn{1}{c}{ UF/Período } & $\mathbf{1 9 9 5 / 9 6}$ & $\mathbf{2 0 0 6}$ \\
\hline Mato Grosso & $\mathrm{R} \$ 27.177$ & $\mathrm{R} \$ 48.353$ \\
São Paulo & $\mathrm{R} \$ 26.389$ & $\mathrm{R} \$ 23.878$ \\
\hline
\end{tabular}

Fonte: Resultados da pesquisa.

Tabela 4. Custo médio da reserva legal, por hectare, em reais de dezembro de 2006, Mato Grosso e São Paulo, anos de 1995/96 e 2006

\begin{tabular}{lccccc}
\hline \multicolumn{1}{c}{ Unidade da Federação (Ano) } & Média & Desvio Padrão & C.V. & Mínimo & Máximo \\
\hline Mato Grosso (1995/96) & 56,19 & 63,07 & 1,122 & 0,00 & 495,73 \\
Mato Grosso (2006) & 117,16 & 205,86 & 1,757 & 0,00 & $1.404,99$ \\
\hline São Paulo (1995/96) & 484,36 & 887,47 & 1,832 & 0,00 & $12.255,49$ \\
São Paulo (2006) & 412,62 & 492,49 & 1,194 & 0,00 & $4.609,65$ \\
\hline
\end{tabular}

Nota: C.V. - Coeficiente de Variação = (desvio padrão / média).

Fonte: Resultados da pesquisa. 
bro de 2006), sendo que o valor máximo também diminuiu de $\mathrm{R} \$ 12,3$ mil para $\mathrm{R} \$ 4,6$ mil por hectare. Esse comportamento é indicativo de que os produtores de São Paulo estão adaptando sua tecnologia de produção de forma a serem menos dependentes em usar a área que deveria ser mantida como reserva legal. Segundo Ehlers (2003), isso pode ser explicado pela fiscalização mais severa, projetos de reflorestamento, aumento da pressão ambiental advinda da sociedade, desenvolvimento da consciência da importância do meio ambiente pelos produtores rurais e desenvolvimento de atividades demandantes das matas, como o ecoturismo.

Para analisar possíveis similaridades e diferenças entre os municípios em seu custo de oportunidade em manter a reserva legal, os valores da equação (3), da seção 3, foram divididos em quantis e plotados em mapas (ver Figuras 1 e 2). Um município classificado no $4^{\underline{O}}$ quartil tem maior custo de oportunidade em relação ao classificado no $1^{\mathrm{O}}$ quartil.

Observa-se que o custo de oportunidade é menor quanto mais ao norte o município está localizado no estado de Mato Grosso (Figura 1), que pode ser explicado pelo maior custo de transporte da produção até os centros consumidores. Entretanto, o custo de oportunidade dos municípios localizados no norte do estado aumentou relativamente aos outros municípios entre 1995 e 2006. Isso pode ser explicado pela expansão da fronteira agrícola nesse estado. Resultado semelhante foi obtido por Young, MacKnight e Meireles (2007), que analisaram o custo de oportunidade da terra em Mato Grosso considerando o cultivo de soja, que assumiram ser o cultivo mais rentável no estado. No estado de São Paulo (Figura 2), municípios localizados no litoral ou oeste apresentaram o menor custo de oportunidade de manter a reserva legal nos estabelecimentos agropecuários. Para o litoral do estado de São Paulo, esse comportamento pode ser explicado pelo ecoturismo nessa região ao se observar a concentração de polos ecoturísticos no litoral do estado ${ }^{17}$ (EHLERS, 2003).

17. Ver mapas para o estado de São Paulo das estâncias turísticas, climáticas, hidrominerais e balneárias (página 208) e polos ecoturísticos (página 211) em Ehlers (2003).
Os resultados obtidos também permitem afirmar que a perda de desempenho dos produtores e o consequente custo de oportunidade advindo da legislação florestal não necessariamente apresentaria alto custo para aqueles produtores que já apresentam baixo desempenho técnico ${ }^{18}$. Ilustrativamente, o município paulista de Alumínio, em 1995, obteve o escore de eficiência técnica de apenas 0,06 , o menor escore dentre todos os municípios e anos analisados, e eficiência ambiental de 0,07. Todavia, o seu Índice de Eficiência Ambiental Baseado nas Folgas (SBEI) foi de 0,87 , que indica que sua receita agropecuária deveria se reduzir em $13 \%\left[(1-0,87)^{*} 100\right]$ ou em $\mathrm{R} \$ 26,94$ por hectare ao diminuir a área de reserva legal utilizada no processo produtivo agropecuário. Assim, apesar do menor escore de eficiência técnica, esse município não possui o maior custo de oportunidade, tanto percentualmente à receita, como em reais por hectare. Entretanto, o município mato-grossense de Sorriso, em 2006, apresentou eficiência técnica de 0,20 e eficiência ambiental de 0,78 , mas apresentou SBEI de apenas 0,25 , o que indica que o aumento em um hectare na área da reserva legal reduziria sua receita agropecuária em $\left.75 \%[1-0,25)^{*} 100\right]$.

Esses resultados contrastam com outros estudos que não incorporaram a ineficiência técnica dos produtores e, assim, não permitiram que o custo de oportunidade apresentasse variações entre os produtores em virtude do seu respectivo nível de eficiência técnica (AZZONI e ISAI, 1994; BACHA, 2005; CAMPOS e BACHA, 2013; IGARATI, TAMBOSI e PIVELLO, 2009). Nesse sentido, os resultados desse estudo indicam que, para alguns produtores, o custo da ineficiência técnica da produção é mais importante do que o custo de oportunidade da reserva legal. Ademais, os resultados mostrados na Tabela 4 indicam a elevada dispersão do custo de oportunidade, ou seja, esse custo não é constante entre os produtores, como os estudos anteriores assumiram ser.

18. A correlação de Spearman entre eficiência técnica e custo de oportunidade para cada estado e ano analisado não foi estatisticamente significativa ao nível de significância de $10 \%$. 
Figura 1. Custo de oportunidade de manter a reserva legal para os municípios mato-grossenses, em reais por hectare, por quartis, para os anos de 1995 e 2006

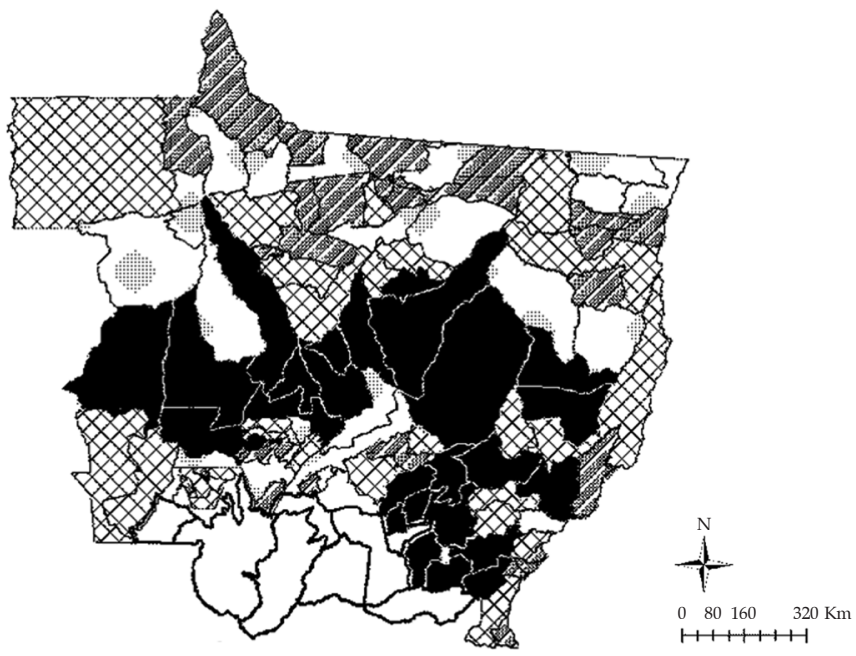

Custo de oportunidade, 1995

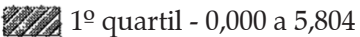

$2^{\circ}$ quartil - 5,805 a 9,342

3o quartil - 9,343 a 17,654

$4^{\text {o }}$ quartil - 17,655 a 876,76

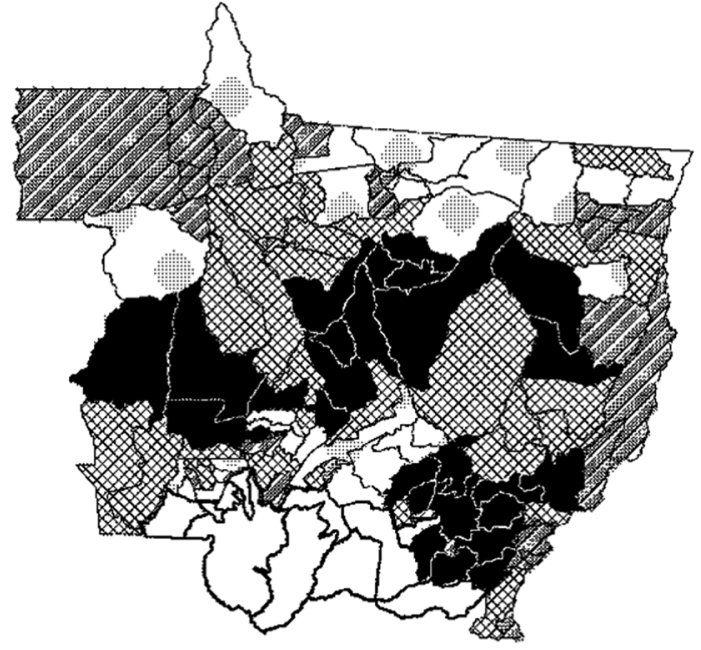

Custo de oportunidade, 2006

10.6. $1^{\circ}$ quartil - 0,000 a 6,679

$72^{\text {o }}$ quartil - 6,679 a 11,291

3o quartil - 11,292 a 22,848

$4^{\mathrm{o}}$ quartil - 22,849 a 1216,454

Fonte: Resultados da pesquisa.

Figura 2. Custo de oportunidade de manter a reserva legal para os municípios paulistas, em reais por hectare, por quartis, para os anos de 1995 e 2006
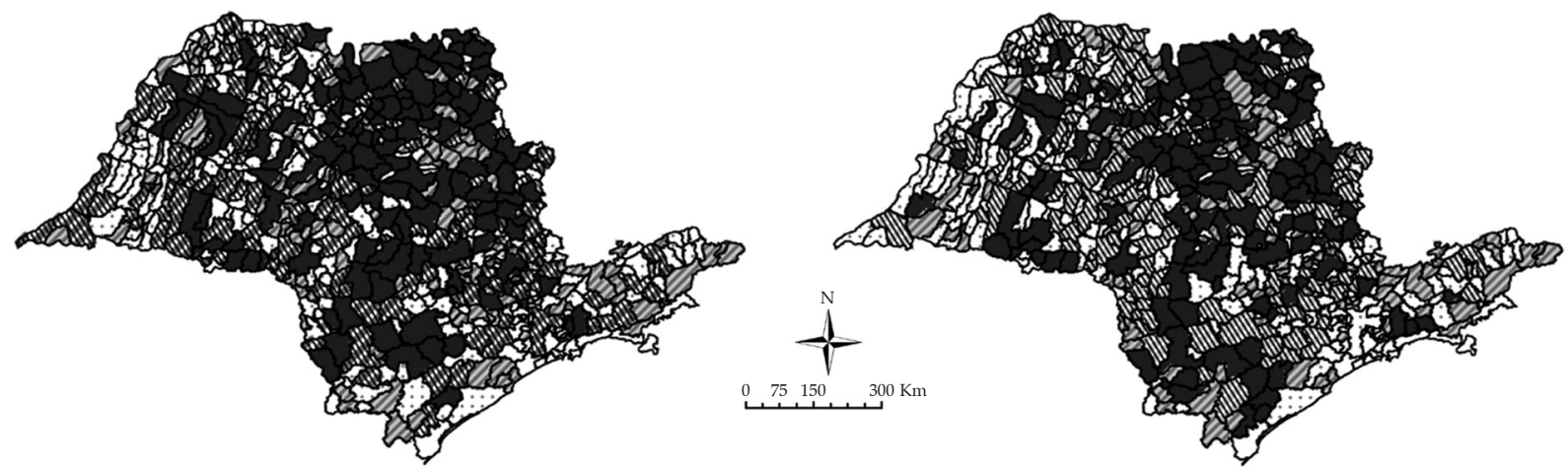

Custo de oportunidade, 1995

UIII $1^{\text {o }}$ quartil - 0,00 a 12,075

2 o quartil - 12,076 a 20,043

3o quartil - 20,044 a 28,995

$4^{\mathrm{o}}$ quartil - 28,996 a 430,031
Custo de oportunidade, 2006

WIIA $1^{\text {o }}$ quartil - 0,000 a 8,653

::i:i: 2o quartil - 8,654 a 17,976

3o quartil - 17,977 a 29,954

$4^{\mathrm{o}}$ quartil - 29,955 a 286,262

Fonte: Resultados da pesquisa. 


\section{Conclusões}

Esse artigo mensurou o custo de oportunidade dos fazendeiros em cumprirem com a obrigação de manutenção da reserva legal dentro de suas propriedades. Esse custo advém do fato de os produtores serem impelidos a gerar benefícios ambientais por meio da legislação florestal via conservação das matas e florestas nativas dentro de sua propriedade, mas não recebem nenhuma contrapartida monetária da sociedade por tal prática. Para tanto, a análise baseou-se em dados dos municípios de São Paulo e Mato Grosso, procurando identificar diferenças regionais desse custo de oportunidade entre e dentro dos estados citados, sendo confrontados os produtores médios do estado de São Paulo e do estado de Mato Grosso entre os anos de 1995/1996 e 2006, utilizando a metodologia proposta por Zhou, Ang e Poh (2006). O produtor médio por município foi obtido ao se dividir o valor total das variáveis de receita, insumos e desmatamento, a nível municipal, pelo respectivo número de estabelecimentos do município.

As estimativas da eficiência técnica e da eficiência técnica ambiental indicaram que, relativamente, São Paulo foi o estado mais eficiente para os anos analisados. Mato Grosso destacou-se pelo baixo desempenho em 1995/96, em que nenhum produtor médio foi eficiente tecnicamente. $\mathrm{O}$ estado de São Paulo também apresentou elevada ineficiência técnica em ambos os anos analisados (1995/96 e 2006), sendo o escore médio de eficiência, para 2006, em São Paulo de 0,30. O desempenho ambiental apresentou melhoria em ambos os estados ao longo do período analisado. Mato Grosso e São Paulo obtiveram o escore de eficiência ambiental de 0,32 e 0,38 em 1995, respectivamente, ao passo que esse escore aumentou para 0,38 e 0,43 em 2006, respectivamente.

A reserva legal apresentou custo implícito aos produtores não desprezível. Por isso, os produtores serão incentivados a utilizar a área que deveria ser mantida como reserva legal no processo produtivo até o ponto em que a receita agropecuária seja igual aos benefícios privados, que será menor do que o socialmente desejado. Para evitar isso, os produtores poderiam ser compensados monetariamente, de forma a manterem a área de reserva legal (que gera benefícios ecológicos para toda a sociedade). Esse incentivo poderia se dar, por exemplo, via redução das taxas de juros do crédito rural. Esses incentivos são necessários para remunerar o produtor em pelo menos os benefícios locais e globais que a sociedade obtém da manutenção da área com reserva legal, como controle da erosão do solo, manutenção e/ ou melhoria da qualidade e quantidade de água, mitigação das mudanças climáticas e proteção contra extremos climáticos e proteção dos recursos genéticos.

Esse estudo contribui, também, ao indicar que o custo de oportunidade de conservar a área da Reserva Legal não é constante entre todos os produtores/municípios. Assim, para que o Brasil possa cumprir a meta de redução dos gases do efeitos estufa e redução do desmatamento ilegal anunciadas na Assembleia Geral da ONU de setembro de 2015 são necessárias políticas públicas que discriminem os produtores conforme o seu custo de manutenção da reserva legal. Isso implicará em maior efetividade das ações de contenção do desmatamento e menor custo.

A existência de dados distribuídos espacialmente permitirá o uso de técnicas de econometria espacial para futuros trabalhos avaliarem efeitos de transbordamento dos tópicos analisados neste artigo. Além disso, à medida que novos dados censitários estejam disponíveis, trabalhos similares poderão avaliar como o custo de oportunidade de manter a reserva legal tem se alterado em relação a 2006.

\section{Referências}

ANDERSEN, L.E. et al. The dynamics of deforestation and economic growth in the Brazilian Amazon. New York: Cambridge University Press, 2002. 259 p.

ANGELSEN, A. Policies for reduced deforestation and their impact on agricultural production. Proceedings of the National Academy of Sciences, Washington, v. 107, n. 46, p. 19639-19644, nov. 2010. 
ANGELSEN, A. e KAIMOWITZ, D. Rethinking the causes of deforestation: Lessons from economic models. The World Bank Research Observer, Oxford, v. 14, n. 1, p. 73-98, Feb. 1, 1999.

AZZONI, C. R. e ISAI, J. Y. Estimating the costs of environmental protection in Brazil. Ecological Economics, Amsterdam, v. 11, n. 2, p. 127-133, nov. 1994.

BACHA, C. J. C Eficácia da política de reserva legal no Brasil. Teoria e Evidência Econômica, Passo Fundo, v. 13, n. 25, p. 9-27, nov. 2005.

BOYD, G. A. e MCCLELLAND, J. D. The impact of environmental constraints on productivity improvement in integrated paper plants. Journal of Environmental Economics and Management, San Diego, v. 38, n. 2, p. 121-142, set. 1999.

BRASIL. Lei n. 4.771, de 15 de setembro de 1965. Institui o novo Código Florestal. Diário Oficial da União, Brasília, 16 set. 1965. p. 9529.

. Ministério do Meio Ambiente. Monitoramento do desmatamento nos biomas brasileiros por satélite: Monitoramento do bioma Pantanal, 2002 a 2008. Brasília: Centro de Informação, Documentação Ambiental e Editoração Luís Eduardo Magalhães, 2010. 30p.

Lei n. 12.727/2012, de 17 de outubro de 2012 Altera a Lei no 12.651, de 25 de maio de 2012, que dispõe sobre a proteção da vegetação nativa; altera as Leis nos 6.938, de 31 de agosto de 1981, 9.393, de 19 de dezembro de 1996, e 11.428, de 22 de dezembro de 2006; e revoga as Leis nos 4.771, de 15 de setembro de 1965 , e 7.754, de 14 de abril de 1989, a Medida Provisória no 2.166-67, de 24 de agosto de 2001, o item 22 do inciso II do art. 167 da Lei no 6.015, de 31 de dezembro de 1973, e o § 2 o do art. 4o da Lei no 12.651, de 25 de maio de 2012. Diário Oficial da União, Brasília, 18 outubro 2012. p. 1 , col. 1 .

CALLAN, S. J. e THOMAS, J. M. Environmental economics $\mathcal{E}$ management: theory, policy, and applications. Mason, $\mathrm{OH}$ : South-Western, Cengage Learning, 2010. 588p

CAMPOS, S. A. C. e BACHA, C. J. C. O custo privado da reserva legal. Revista de Política Agrícola, Brasília, v. 22, n. 2, p. 85-104, abr./jun. 2013.

CARNEIRO, S. L. Estudo prospectivo da implantação da reserva legal em propriedades rurais familiares representativas de sistemas de produção de grãos na região de Londrina - estado do Paraná. 2005. 209 p. Dissertação (Mestrado em Administração) - Universidade Estadual de Londrina e Universidade Estadual de Maringá, Londrina. 2005
COELLI, T. J., LAUWERS, L. e HUYLENBROECK, G. Environmental efficiency measurement and the materials balance condition. Journal of Productivity Analysis, Houston, v. 28, n. 1-2, p. 3-12, out. 2007.

.et al. An introduction to efficiency and productivity analysis. $2^{\text {nd }}$. New York: Springer, 2005. 348 p.

EHLERS, E. M. Determinantes da recuperação da mata atlântica no estado de São Paulo. 2003. 351 p. Tese (Doutorado em Ciência Ambiental), Universidade de São Paulo, São Paulo, 2003.

FÄRE, R., GROSSKOPFA, S. e TYTECA, D. An activity analysis model of the environmental performance of firms-application to fossil-fuel-fired electric utilities. Ecological Economics, Amsterdam, v. 18, n. 2, p. 161-175, ago. 1996.

FASIABEN, M. D. C. R. et al. Impacto econômico da reserva legal sobre diferentes tipos de unidades de produção agropecuária. Revista de Economia e Sociologia Rural, Piracicaba, v. 49, p. 1051-1096, out./dez. 2011.

FUNDAÇÃO GETÚLIO VARGAS. Índices economicos. Revista Conjuntura Econômica, Rio de Janeiro, v. 50, n. 12 , p. 58-59, dez. 1996.

- Índices Economicos. Revista Conjuntura Econômica, Rio de Janeiro, v. 61, n. 6, p. 87, jun. 2007.

. Preços Agropecuários. Disponível em: < http:// www.antigofgvdados.fgv.br/dsp_gratuitas.asp $>$. Acesso em: 26 fev. 2014.

GIAMPIETRO, M. Socioeconomic pressure, demographic pressure, environmental loading and technological changes in agriculture. Agriculture, Ecosystems \& Environment, Amsterdam, v. 65, n. 3, p. 201-229, nov. 1997.

HUHTALA, A. e MARKLUND, P.-O. Stringency of environmental targets in animal agriculture: shedding light on policy with shadow prices. European Review of Agricultural Economics, v. 35, n. 2, p. 193-217, 2008.

INSTITUTO BRASILEIRO DE GEOGRAFIA E ESTATÍSTICA. Censo Agropecuário 1995-1996: Brasil. Rio de Janeiro: IBGE, 1998, p. 1-358.

Censo Agropecuário 2006: Brasil, Grandes Regiões e Unidades da Federação. Rio de Janeiro: IBGE, 2009. p. 1-777.

IGARI, A., TAMBOSI, L. e PIVELLO, V. Agribusiness opportunity costs and environmental legal protection: investigating trade-off on hotspot preservation in the state of São Paulo, Brazil. Environmental Management, London, v. 44, n. 2, p. 346-355, 2009. 
KEIL, A., BIRNER, R. e ZELLER, M. Potentials to reduce deforestation by enhancing the technical efficiency of crop production in forest margin areas. In: TSCHARNTKE, T. et al. (Eds.). Stability of tropical rainforest margins: linking ecological, economic and social constraints of land use and conservation. Germany: Springer, 2007. p. 389-414.

LEE, J.-D., PARK, J.-B. e KIM, T.-Y. Estimation of the shadow prices of pollutants with production/ environment inefficiency taken into account: a nonparametric directional distance function approach. Journal of Environmental Management, London, v. 64, n. 4, p. 365-375, 2002.

PAIVA, C. A (Org.). Evolução das desigualdades territoriais no Rio Grande do Sul. Santa Cruz do Sul: Edunisc, 2008.

. Uma alternativa à metodologia das AMCs. RMSD, 2007. Disponível em: <http://www.fee.tche.br/rs-emmapas-e-dados/index.html>. Acesso em: 18 jan. 2014.

PERMAN, R. et al. Natural resource and environmental economics. Harlow, England New York: Harlow, England Pearson Addison Wesley New York, 2003. 728p.

PICAZO-TADEO, A. J., REIG-MARTÍNEZ, E. e HERNÁNDEZ-SANCHO, F. Directional distance functions and environmental regulation. Resource and Energy Economics, Amsterdam, v. 27, n. 2, p. 131-142, jun. 2005.

PIOT-LEPETIT, I., VERMERSCH, D. e WEAVER, R. D. Agriculture's environmental externalities: DEA evidence for French agriculture. Applied Economics, London, v. 29, n. 3, p. 331-338, mar. 1997

RICHARD, H. L. e LEFTWICH, R. H. Introduction to microeconomics. New York: New York Holt, Rinehart and Winston, 1970.

SHARP J. A., MENG, W. e LIU, W. A modified slackbased measure model for data envelopment analysis with natural negative outputs and inputs. Journal of the Operational Research Society, Basingstoke, v. 58, n. 12, p. 1672-1677, dez. 2007.

SIPILÄINEN, T. e HUHTALA, A. Opportunity costs of providing crop diversity in organic and conventional farming: would targeted environmental policies make economic sense? European Review of Agricultural Economics, Oxford, v. 40, n. 3, p. 441-462, jul. 2013.

SIQUEIRA, C. F. A. Aspectos econômicos de conservação de florestas em terras privadas: o Código Florestal e a reserva legal na Amazônia. 2004. 112p. Dissertação (Mestre em Ciências) - Uniersidade de Brasília, Brasília, 2004.

SOUZA, G. S. e GOMES, E. G. Improving agricultural economic efficiency in Brazil. International Transactions in Operational Research, Oxford, v. 22, n. 2, p. 329-337, mar. 2015.

SUN, C. et al. Water resource utilization efficiency and spatial spillover effects in China. Journal of Geographical Sciences, Beijing, v. 24, n. 5, p. 771-788, out. 2014.

TONE, K. A slacks-based measure of efficiency in data envelopment analysis. European Journal of Operational Research, Amsterdam, v. 130, n. 3, p. 498-509, maio 2001.

. Dealing with undesirable outputs in dea: A slaeks-based measure (SBM) approach. GRIPS Research Report Series, Toronto, v. 2004, p. 44-45, June 2004.

WILSON, P., HADLEY, D. e ASBY, C. The influence of management characteristics on the technical efficiency of wheat farmers in eastern England. Agricultural Economics, Amsterdam, v. 24, n. 3, p. 329-338, mar. 2001.

YOUNG, C. E. F., MAC-KNIGHT, V. e MEIRELES, A. L. C. Desmatamento e custo de oportunidade da terra: o caso do Mato Grosso. In: ENCONTRO NACIONAL DA SOCIEDADE BRASILEIRA DE ECONOMIA ECOLÓGICA, 2007, Fortaleza. Anais... Fortaleza: Encontro Nacional da Sociedade Brasileira de Economia Ecológica, 2007. p. 1-26.

ZHOU, P., ANG, B. W. e POH, K. L. Slacks-based efficiency measures for modeling environmental performance. Ecological Economics, Amsterdam, v. 60, n. 1, p. 111-118, nov. 2006.

. Measuring environmental performance under different environmental DEA technologies. Energy Economics, Amsterdam, v. 30, n. 1, p. 1-14, jan. 2008.

ZOFÍO, J. L. e PRIETO, A. M. Environmental efficiency and regulatory standards: the case of $\mathrm{CO} 2$ emissions from OECD industries. Resource and Energy Economics, Amsterdam, v. 23, n. 1, p. 63-83, jan. 2001. 
